\title{
EVALUASI PENERAPAN SASARAN KESELAMATAN PASIEN DI UPT PUSKESMAS RAWAT INAP SUKOHARJO PRINGSEWU LAMPUNG (STUDI KASUS PASCA AKREDITASI)
}

\author{
Rinto Hadiarto ${ }^{1}$, Fitri Ekasari², Vera Yulyani ${ }^{2}$
}

1 Mahasiswa, Program Studi Magister Kesehatan Masyarakat, Universitas Malahayati ${ }^{2}$ Dosen, Program Studi Magister Kesehatan Masyarakat, Universitas Malahayati

\begin{abstract}
Evaluation of the Implementation of Patient Safety Goals at UPT Puskesmas Rawat Inap Sukoharjo Pringsewu Lampung (Post Accreditation Case Study). Patient safety is not only applied in hospitals but also in all health service facilities, one of which is the puskesmas. From the data on Clinical Quality Improvement and Patient Safety (PMKP) UPT Puskesmas Rawat Inap Sukoharjo in 2017, there are still patient safety incidents and the target of six patient safety targets has not been achieved. The purpose of this study was to obtain a more indepth description or information about the evaluation of the implementation of patient safety goals at the UPT Puskesmas Rawat Inap Sukoharjo Pringsewu Lampung in 2020. This type of research is qualitative with a case study approach. Collecting data through in-depth interviews, FGD, document review and observation. Informants of 20 people who were taken by purposive sampling. The components studied are related to inputs (human resources, funds, facilities and infrastructure, policies and SOPs). The process is the implementation of patient safety goals. Output of implementation performance. Data analysis used an interactive model and data validity with triangulation techniques of data sources. The results of the research were that the PMKP team's input component was formed but it has not worked optimally. There is no special fund for patient safety. Some of the facilities and infrastructure are missing. Policies and SOPs already exist and are socialized. The process is not optimal, because not all officers have implemented it and it has not become a culture for officers. Output has not reached the expected target with an average value of $74.03 \%$ (100\% standard
\end{abstract}

Keywords : Patient Safety Goals,Community Health Center, Input, Process, Output

\begin{abstract}
Abstrak: Evaluasi Penerapan Sasaran Keselamatan Pasien di UPT Puskesmas Rawat Inap Sukoharjo Pringsewu Lampung (Studi Kasus Pasca Akreditasi). Keselamatan pasien tidak hanya diterapkan di rumah sakit namun juga pada seluruh fasilitas pelayanan kesehatan salah satunya yaitu puskesmas. Dari data Peningkatan Mutu Klinis dan Keselamatan Pasien (PMKP) UPT Puskesmas Rawat Inap Sukoharjo tahun 2017, masih terdapat insiden keselamatan pasien dan belum tercapainya target enam sasaran keselamatan pasien. Tujuan penelitian ini adalah mendapatkan gambaran atau informasi yang lebih mendalam tentang evaluasi penerapan sasaran keselamatan pasien di UPT Puskesmas Rawat Inap Sukoharjo Pringsewu Lampung tahun 2020. Jenis penelitian ini kualitatif dengan pendekatan studi kasus. Pengumpulan data melalui wawancara mendalam, FGD, telaah dokumen dan observasi. Informan 20 orang yang diambil dengan teknik purposive sampling. Komponen yang diteliti mengenai input (sumber daya manusia, dana, sarana dan prasarana, kebijakan dan SOP). Proses yaitu pelaksanaan penerapan sasaran keselamatan pasien. Output dari capaian penerapan. Analisis data menggunakan model interaktif serta validitas data dengan teknik triangulasi sumber data. Hasil penelitian komponen input tim PMKP dibentuk namun belum bekerja optimal. Belum ada dana khusus untuk keselamatan pasien. Sarana dan prasarana ada beberapa yang kurang. Kebijakan dan SOP sudah ada dan disosialisasikan. Proses belum maksimal, karena belum semua petugas melaksanakan dan belum menjadi budaya bagi petugas. Output belum mencapai target yang diharapkan dengan nilai rata-rata capaian 74,03\% (standar 100\%).

Kata Kunci : Keselamatan Pasien, Puskesmas, Input, Proses, Output
\end{abstract}




\section{PENDAHULUAN}

Keselamatan pasien merupakan sebuah sistem yang membuat asuhan pasien lebih aman. Sistem tersebut terdiri dari asesmen risiko, identifikasi dan pengelolaan risiko pasien, pelaporan dan analisis insiden, kemampuan belajar dari insiden dan tindak lanjutnya, serta implementasi solusi untuk meminimalkan timbulnya risiko dan mencegah terjadinya cedera yang disebabkan oleh kesalahan akibat melakukan suatu tindakan atau tidak mengambil tindakan yang seharusnya diambil (Permenkes R.I No 11, 2017). Perkembangan tentang isu keselamatan pasien di puskesmas tidak sedinamis seperti di tingkat rumah sakit. Padahal jumlah rumah sakit tidak sebanding dengan jumlah puskesmas, yang mana jumlah puskesmas lebih banyak dari pada rumah sakit yang ada di Indonesia (Islami, Arso and Lestantyo, 2018). Indonesia merupakan satusatunya negara di dunia yang melakukan akreditasi puskesmas (Kementerian Kesehatan Republik Indonesia, 2019). Penyelenggaraan akreditasi puskesmas dilakukan secara bertahap kepada 9.740 puskesmas di Indonesia, begitu pula kepada 13 puskesmas di Kabupaten Pringsewu yang berada di provinsi Lampung. Pada tahun 2018, Dinas Kesehatan Kabupaten Pringsewu telah melakukan akreditasi terhadap 6 puskesmas salah satunya adalah Unit Pelayan Teknis (UPT) Puskesmas Rawat Inap Sukoharjo (Dinas Kesehatan Kabupaten Pringsewu, 2017). Berdasarkan survei pendahuluan, UPT Puskesmas Rawat Inap Sukoharjo telah membentuk Tim Peningkatan Mutu Klinis dan Keselamatan Pasien (PMKP). Tim PMKP sudah melaksanakan perencanaan, pelaksanaan, dan evaluasi pada tahun 2017 dari bulan Januari sampai Juli dengan hasil laporan KTD 5 kejadian, KPC 3 kejadian, KTC 1 kejadian, dibandingkan dengan target nasional tentang insiden keselamatan pasien 0 untuk kasus KTD dan KNC.

Berdasarkan survei dokumen dari PMKP UPT Puskesmas Rawat Inap
Sukoharjo telah menerapkan enam sasaran keselamatan pasien di UPT Puskesmas Rawat Inap Sukoharjo. Hasil penerapan sasaran keselamatan pasien tahun 2017 mencapai 69,58\%. Pada capaian penerapan sasaran keselamatan pasien (SKP) yang pertama tidak terjadinya kesalahan identifikasi pasien yaitu $70 \%$, untuk capaian SKP kedua peningkatan komunikasi efektif yaitu 62,5\%, capaian SKP ketiga tidak terjadinya kesalahan pemberian obat yaitu $75 \%$, capaian SKP keempat tidak terjadinya kesalahan prosedur tindakan medis dan keperawatan yaitu $60 \%$, capaian SKP kelima pengurangan terjadinya risiko infeksi di Puskesmas yaitu $75 \%$ dan capaian SKP keenam tidak terjadinya pasien jatuh yaitu $75 \%$ karena masih adanya insiden pasien jatuh.Angka tersebut menunjukkan belum tercapainya target yang diharapkan, yaitu target $100 \%$ untuk semua sasaran keselamatan pasien yang ditetapkan berdasarkan keputusan Kepala UPT Puskesmas Rawat Inap Sukoharjo tentang sasaran-sasaran keselamatan pasien yang mengacu pada Peraturan Menteri Kesehatan Republik Indonesia No. 11 tahun 2017 tentang Keselamatan Pasien.

Dari pemaparan penulis terhadap permasalahan di atas bahwa masih terdapat insiden keselamatan pasien dan belum tercapainya target enam sasaran keselamatan pasien di UPT Puskesmas Rawat Inap Sukoharjo, maka peneliti tertarik untuk melakukan evaluasi penerapan sasaran keselamatan pasien di UPT Puskesmas Rawat Inap Sukoharjo Pringsewu Lampung tahun 2020. Tujuan penelitian ini adalah mendapatkan gambaran atau informasi yang lebih mendalam tentang evaluasi penerapan sasaran keselamatan pasien di UPT Puskesmas Rawat Inap Sukoharjo Pringsewu Lampung tahun 2020 dengan menganalisis input, proses, output. 
METODE

Jenis penelitian ini adalah penelitian kualitatif dengan pendekatan studi kasus. Pengumpulan data melalui wawancara mendalam, $F G D$, telaah dokumen dan observasi. Informan 20 orang yang diambil dengan teknik purposive sampling terdiri dari : ketua PMKP, ketua mutu, kepala puskesmas, kepala rawat jalan, kepala rawat inap, dokter umum, perawat, perawat gigi, bidan, nutrisionis, asisten apoteker, analis laboratorium, petugas pendaftaran, pasien rawat jalan dan rawat inap. Komponen yang diteliti mengenai input (sumber daya manusia, dana, sarana dan prasarana, kebijakan dan SOP). Proses yaitu pelaksanaan penerapan sasaran keselamatan pasien. Output dari capaian penerapan. Lokasi penelitian di Puskesmas Rawat Inap Sukoharjo. Analisis data menggunakan model interaktif serta validitas data dengan teknik triangulasi sumber data.

\section{HASIL}

\section{A. Karakteristik Informan}

Karakteristik informan yang dibahas dalam studi ini meliputi umur, jenis kelamin, pendidikan, pekerjaan. Karakteristik informan dapat dilihat di tabel berikut.

Tabel 1. Karakteristik Informan Kunci

\begin{tabular}{lclll}
\hline Kode Informan & Usia & JK & Pendidikan & Pekerjaan \\
\hline If.1 & 28 & P & S1 & Dokter umum \\
If.2 & 43 & P & S1 & Bidan \\
If.3 & 37 & P & S1 & Dokter umum \\
If.4 & 40 & L & S1 & Perawat \\
If.5 & 53 & L & S1 & Perawat \\
\hline
\end{tabular}

Tabel.2 Karakteristik Informan Focus Group Discussion Profesi

\begin{tabular}{lllll}
\hline Kode Informan & Usia & JK & Pendidikan & Pekerjaan \\
\hline Ifg.1 & 25 & P & S1 & Dokter umum \\
Ifg.2 & 34 & P & D3 & Perawat \\
Ifg.3 & 55 & P & D3 & Perawat Gigi \\
Ifg.4 & 46 & P & D3 & Bidan \\
Ifg.5 & 34 & P & S1 & Nutrisionis/Petugas Gizi \\
Ifg.6 & 33 & P & D3 & Asisten Apoteker \\
Ifg.7 & 44 & P & D3 & Analis Laboratorium \\
Ifg.8 & 52 & P & S1 & Petugas Pendaftaran \\
\hline
\end{tabular}

Tabel.3 Karakteristik Informan Focus Group Discussion Pasien

\begin{tabular}{lllll}
\hline Kode Informan & Usia & JK & Pendidikan & Pekerjaan \\
\hline Ips.1 & 37 & L & SMA & Petugas TU \\
Ips.2 & 38 & L & SMP & Cleaning Service \\
Ips.3 & 65 & P & SD & IRT \\
Ips.4 & 60 & L & SD & Petani Kebun Coklat \\
Ips.5 & 55 & L & SMA & Satpam \\
Ips.6 & 63 & P & SD & IRT \\
Ips.7 & 50 & P & SD & Pembantu Rumah Tangga \\
\hline
\end{tabular}

1. Komponen Input

a. Sumber Daya Manusia

Semua informan kunci mengatakan yang bertanggung jawab dalam pelaksanaan sasaran keselamatan pasien adalah semua petugas yang memberikan pelayanan kesehatan terhadap pasien, seperti yang dijelaskan oleh informan berikut ini :

"...Petugas yang bertanggung jawab terhadap keselamatan pasien adalah semua petugas kesehatan yang memberikan pelayanan kesehatan terhadap pasien..." (If.3) 
Sebagian besar informan kunci mengatakan ada ketua atau koordinator dan tim PMKP di UPT Puskesmas Rawat Inap Sukoharjo, seperti yang dijelaskan informan berikut ini :

"...Untuk keselamatan pasien kita ada tim keselamatan pasien yang diketuai oleh MR, ada anggota lain yaitu sekretaris dan anggota. Kalau tidak salah ada sekitar delapan orang..." (If.2)

"...Iya sama semua petugas bertanggung jawab terhadap keselamatan pasien. Untuk tenaga bidan sudah cukup dan sepertinya dulu sudah disosialisasikan tentang keselamatan pasien ada ketua dan tim PMK itu dibentuk saat akreditasi..." (Ifg.4)

Sebagian kecil informan FGD profesi mengatakan ada ketua dan tim PMKP yang bertanggung jawab langsung tentang keselamatan pasien, perlu penerimaan dokter gigi, perawat jaga di rawat inap tidak sesuai dengan jumlah pasien yang banyak. Seperti yang dijelaskan informan berikut ini : "...Semua petugas utamanya, tapi iya ada ketua khusus itu. MR sebagai ketua PMKP namun sepertinya belum berjalan baik. Di bagian obat sudah cukup dibantu oleh perekrutan tenaga apoteker baru, yang baru belum tersosialisasi yang lama sudah....." (Ifg.6)

"...Iya sama semua petugas kesehatan. Untuk perawat gigi cukup, untuk pelayanan gigi kami mengusulkan agar dilakukan penerimaan dokter gigi. Sudah terpapar kok tentang sosialisasi keselamatan pasien..."( Ifg.3)

"...Iya sama semua petugas bertanggung jawab. Kalau jumlah perawat di pelayanan rawat jalan dan rawat inap cukup, walau terkadang di rawat inap tidak sesuai antara perawat yang jaga dengan pasien yang banyak. Sudah disosialisasikan tentang keselamatan pasien...." (Ifg.2)

\section{b. Dana}

Sebagian besar informan
kunci mengatakan untuk ketersediaan dana pelaksanaan program keselamatan pasien di UPT Puskesmas Rawat Inap Sukoharjo memang belum ada dana khusus yang dianggarkan dalam RBA. Seperti yang dijelaskan informan berikut ini: "...Sejauh ini belum pernah dapat dana untuk keselamatan pasien, karena kita juga belum pernah mengajukan, jadi belum pernah dapat dana dari puskesmas. Keselamatan pasien memang menjadi prioritas, sangat diprioritaskan, namun belum pernah ada alokasi dana khusus untuk keselamatan pasien. Iya harus ada perencanaan masuk RBA agar ada dana khusus untuk keselamatan pasien. Alokasi dana bisa menggunakan BOK saja mungkin sudah cukup..." (If.1) Semua informan FGD profesi mengatakan tidak ada dana yang di khususkan untuk keselamatan pasien. Seperti yang dijelaskan informan berikut ini :

"...Memang selama ini tidak ada dana khusus untuk keselamatan pasien, tapi untuk perawatan di gedung puskesmas biasanya ada di RBA..." (Ifg.2)

"...Keselamatan pasien belum menjadi prioritas utama dalam pendanaan karena masih ada program esensial..." (Ifg.4)

\section{c. Sarana Prasarana}

Sebagian kecil informan kunci mengatakan masih ada beberapa sarana dan prasarana yang kurang menunjang dalam pelaksanaan sasaran keselamatan pasien. Seperti yang dijelaskan informan berikut ini:

"...Sudah, itu sudah ada di puskesmas, seperti pegangan tangan di kamar mandi, gelang pasien ada, tempat cuci tangan ada, tempat tidur yang ada penghalangnya juga ada tapi memang belum semua tempat 
tidur ada penghalangnya mudahmudahan semakin hari semakin memperbaiki untuk keselamatan pasien. Untuk sarana dan prasarana tetap harus ada pengajuan di dinas. Dilain pihak karena puskesmas telah BLUD maka bisa untuk pengadaan sendiri itu mungkin untuk kedepannya..."(If.3)

Sebagian besar informan FGD profesi mengatakan tentang kecukupan sarana dan prasarana untuk pelaksanaan sasaran keselamatan pasien sudah mencukupi. Seperti yang dijelaskan informan berikut ini : "...Sarana dan prasarana cukup, jika ada kerusakan biasanya kita lapor dan akan ditindaklanjuti oleh manajemen puskesmas. Iya belum ada telpon antar unit pelayanan untuk memudahkan dalam menyampaikan informasi terkait pasien..."(Ifg.7)

Sebagian kecil Informan FGD profesi mengatakan sabun cuci tangan, handscrub atau tisu sering habis. Seperti yang dijelaskan Informan FGD profesi berikut ini :

"...Tidak semua ruangan ada tempat cuci tangannya. Iya jadi kita pakai handscrub yang menjadi kendala adalah sabun cuci tangan, handscrub atau tisu sering habis..." (Ifg.4)

Sebagian kecil Informan FGD profesi mengatakan masih ada tempat tidur yang belum ada penghalangnya. Seperti yang dijelaskan informan berikut ini : "...Belum terpenuhi masih kurang di IGD rawat inap contohnya bed atau tempat tidur masih ada bed yang belum ada penghalangnya, risiko jatuh jadinya, harusnya dikasih tanda risiko jatuh, jadi masih kurang yang ada penghalangnya paling seperti brankar pasien untuk merujuk..."(Ifg1)

\section{d. Kebijakan dan SOP}

kunci mengatakan informan kebijakan dan SOP sasaran keselamatan pasien sudah ada, sudah sesuai permenkes dan undang-undang, sudah disosialisasikan ke petugas dan masih terkendala monitoring dan evaluasi yang belum konsisten. Seperti yang dijelaskan informan berikut ini:

"...Kebijakan dan SOP sudah ada, kebijakan dan SOP sudah sesuai permenkes dan UndangUndang. Sebelumnya kita sosialisasikan kepada petugas puskesmas, dan terkadang kita monitoring tiap bulannya seperti kejadian-kejadian tidak diharapkan. Kita monitoring tiap bulan kalau untuk saat ini sudah cukup Kebijakan atau SOP yang ada, kalau untuk ditambahkan itu bisa ditambahkan masukanmasukan, kritikan bisa dimasukkan di SOP. Kalau untuk diganti atau dirubah itu tidak, sudah cukup..."(if.1)

Semua informan FGD profesi mengatakan untuk kebijakan dan SOP tentang keselamatan pasien sudah ada. Seperti yang dijelaskan informan berikut ini :

"... Kebijakan sudah ada, SOP
juga sudah lengkap...tapi
pelaksanaannya masih belum
konsisten...kadang
dilaksanakan..kadang ngak
dilaksanakan..." (Ifg.1)

Sebagian kecil informan FGD profesi mengatakan pelaksanaan sasaran keselamatan pasien tidak maksimal karena belum menjadi budaya oleh petugas. Seperti yang dijelaskan informan berikut ini :

"..Kebijakan dan SOP sudah lengkap dibuat pada saat akreditasi kemarin, namun saat ini pelaksanaannya tidak maksimal karena belum menjadi budaya oleh petugas.." (Ifg.5) 


\section{Komponen Proses}

Sebagian besar informan kunci mengatakan untuk proses pelaksanaan sasaran keselamatan pasien di UPT Puskesmas Rawat Inap Sukoharjo masih belum semua petugas melaksanakan. Seperti yang dijelaskan informan berikut ini:

"...Setelah dievaluasi belum semua melaksanakan sasaran keselamatan pasien..belum semua tenaga kesehatan melaksanakan keselamatan pasien...banyak juga tenaga baru..jadi kita harus sosialisasi dan orientasi lah..komunikasi efektif mungkin yang menjadi catatannya..karena untuk tenaga medis kita harus mempunyai suatu keahlian tertentu salah satunya komunikasi pasien.. terkadang apa yang disampaikan tenaga medis berbeda dengan apa yang diterima oleh pasien..mungkin bisa dari logatnya, nadanya, kekerasan suaranya itu yang bisa menjadi hambatan..." (If.3)

Sebagian kecil informan FGD profesi mengatakan pelaksanaan sasaran keselamatan pasien sudah dilaksanakan. Seperti yang dijelaskan informan berikut ini :

$$
\text { "...Kalau ditanya sudah }
$$

dilaksanakan penerapan sasaran keselamatan pasien? jawabannya sudah tapi mungkin perlu monev..sepertinya di buku rekam medis gak ada surgical checklist.. iya memang gak ada form penilaian risiko jatuh memang belum ada di list/rekam medis..."(Ifg.4)

Sebagian kecil informan FGD profesi mengatakan dalam komunikasi efektif belum menggunakan standarisasi komunikasi melalui metode Situation Background Assessment Recommendation (SBAR). Seperti yang dijelaskan informan berikut ini :

$$
\text { "...Penerapan dari keenam }
$$
sasaran ini masih kurang, meskipun sudah ada SOP..iya belum belum menggunakan standarisasi komunikasi melalui metode Situation Background Assessment Recommendation (SBAR)..iya belum punya standar operasional prosedur surgical checklist..kalau form penilaian risiko jatuh memang belum ada di list/rekam medis..."(Ifg.1)

Sebagian kecil informan FGD profesi mengatakan belum punya standar operasional prosedur surgical checklist. Seperti yang dijelaskan informan berikut ini :

$$
\text { "...Untuk melaksanakan }
$$

keenam Sasaran Keselamatan Pasien tersebut sepertinya belum maksimal, masih ada perawat yang belum terbiasa melaksanakan sasaran keselamatan pasien.. seperti komunikasi efektif di puskesmas rawat inap sukoharjo belum menggunakan standarisasi komunikasi melalui metode Situation Background Assessment Recommendation (SBAR), kayaknya belum punya standar operasional prosedur surgical checklist..."(Ifg.2)

Sebagian kecil informan FGD profesi mengatakan pernah terjadi kesalahan pemberian obat. Seperti yang dijelaskan informan berikut ini : "...Kalau di apotik atau ruang obat itu pernah terjadi kesalahan pemberian obat expired tapi pasien tidak cidera selain itu juga pernah tertukar obat karena namanya sama..nggak sampai insiden keselamatan pasien karena langsung telusur..."(Ifg.6)

Sebagian kecil informan FGD profesi mengatakan belum ada form penilaian risiko jatuh. Seperti yang dijelaskan informan berikut ini :

$$
\text { "...Kalau ditanya sudah }
$$

dilaksanakan penerapan sasaran keselamatan pasien? jawabannya sudah tapi mungkin perlu monev..sepertinya di buku Rekam Medis gak ada surgical checklist.. iya memang gak ada form penilaian risiko jatuh memang belum ada di list/rekam medis..."(Ifg.4)

Peneliti juga melakukan FGD pada pasien, semua informan FGD pasien mengatakan pelayanan rawat jalan atau rawat inap di UPT Puskesmas Rawat Inap Sukoharjo cukup baik. Seperti yang dijelaskan informan berikut ini : 
"...Alhamdulilah pelayanan cukup baik.mungkin ada yang kurang tapi sangat sedikit..."(Ip.5)

Sebagian besar informan FGD pasien mengatakan tidak pernah terjadi kesalahan pemberian obat. Seperti yang dijelaskan informan berikut ini :

"...Nggak pernah terjadi kesalahan pemberian obat..."(Ip.6)

"...Iya saya juga gak pernah mendapatkan kesalahan pemberian obat..."(Ip.7)

Sebagian besar informan FGD pasien mengatakan petugas kesehatan melakukan cuci tangan. Seperti yang dijelaskan informan FGD pasien berikut ini :

$$
\text { "...Iya petugas cuci }
$$

tangan..terkadang pakai handscoon juga..."( Ip.2)

Sebagian besar informan FGD pasien mengatakan untuk tempat tidur pasien tidak semua ada penghalangnya. Seperti yang dijelaskan informan berikut ini : "...Iya untuk tempat tidur kayaknya ada yang penghalangnya ada juga yang nggak ada...kamar mandi juga sama kayaknya...."(Ip.5)

\section{Komponen Output}

Output merupakan elemen yang dihasilkan dari berfungsinya proses dalam sistem. Sebagian besar informan kunci mengatakan untuk output dari pelaksanaan sasaran keselamatan pasien di UPT Puskesmas Rawat Inap Sukoharjo secara keseluruhan hasil pelaksanaan SKP masih perlu perbaikan.

ini:

Seperti yang dijelaskan berikut

"...Kalau kita selalu berusaha untuk memperbaiki dalam penerapan sasaran keselamatan pasien seperti komunikasi efektif pada pasien, hari ke hari, tahun ke tahun kita lengkapi lah apa saja yang menjadi kekurangan, mulai dari pendaftaran di identifikasi nama, keterbatasan bahasa, psikologisnya, pokoknya di perbaiki semuanya..enam sasaran keselamatan pasien itu bisa diterapkan semuanya di puskesmas karena kita sebagai pelayan publik harus menerapkan enam sasaran keselamatan pasien..dan semua tenaga kesehatan bertanggung jawab dalam sasaran keselamatan pasien..."(If.3)

Semua informan FGD profesi mengatakan mengenai hasil pelaksanaan enam sasaran keselamatan pasien di UPT Puskesmas Rawat Inap Sukoharjo sudah cukup. Seperti yang dijelaskan informan FGD profesi berikut ini :

"...Menurut saya sudah cukup walau masih ada beberapa yang mungkin perlu perbaikan seperti baik itu kepatuhan petugas, sarana prasarana yang kurang..."(Ifg.1)

\section{PEMBAHASAN}

\section{Komponen Input}

a. Sumber Daya Manusia

Dari hasil FGD (Focus Group Discussion) didapatkan informasi bahwa UPT Puskesmas Rawat Inap Sukoharjo telah membentuk tim Peningkatan Mutu Klinis dan Keselamatan Pasien (PMKP) yang terdiri dari ketua dan anggota. Hal ini sejalan dengan penelitian (Neri, Lestari and Yetti, 2018) menjelaskan dari hasil penelitiannya didapatkan tim keselamatan pasien RSUP Dr. M. Djamil Padang yang telah dibentuk belum bekerja secara optimal. Tim Keselamatan pasien RSUP Dr. M. Djamil Padang belum pernah menyusun program kerja, pembagian tugas, dan belum pernah melakukan monitoring dan evaluasi terkait pelaksanaan sasaran keselamatan pasien. Menurut pendapat peneliti seyogyanya tim PMKP puskesmas bertugas melaksanakan monitoring dan evaluasi program keselamatan pasien, merekap pencatatan dan pelaporan insiden, analisis insiden termasuk melakukan RCA (Root Cause Analysis). Yang menjadi permasalahannya adalah ada penanggung jawab program dalam hal ini ketua PMKP dan tim PMKP sudah di bentuk, namun tim PMKP belum berjalan sebagaimana mestinya. Tim PMKP juga perlu diberikan pelatihan dan dapat mensosialisasikan kepada 
semua staf tiap tahun agar petugas kesehatan mendapatkan penyegaran materi, menerapkan sasaran keselamatan pasien yang berkesinambungan, dan berkomitmen dalam pelayanan yang mementingkan keselamatan pasien. Puskesmas juga perlu melihat kebutuhan sumber daya manusia yang kompeten berdasarkan analisis kebutuhan jabatan.

\section{b. Dana}

Berdasarkan

wawancara mendalam dengan informan kunci mengatakan sebagian besar informan kunci mengatakan untuk ketersediaan dana pelaksanaan program keselamatan pasien di UPT Puskesmas Rawat Inap Sukoharjo memang belum ada dana khusus yang dianggarkan dalam RBA. Berdasarkan FGD profesi mengatakan semua informan FGD profesi mengatakan tidak ada dana yang di khususkan untuk keselamatan pasien. Berdasarkan telaah dokumen didapatkan pada rencana bisnis anggaran (RBA) Berdasarkan hasil observasi adanya permintaan kebutuhan per tahun dari instalasi terkait kebutuhan alat kesehatan, bahan medis habis pakai, kebutuhan pelayanan, dan pelatihanpelatihan. Anggaran tersebut melekat hanya pada kegiatan bidang pelayanan dan bidang penunjang (RBA Puskesmas Rawat Inap Sukoharjo, 2020). Hal ini sejalan dengan penelitian Islami (2018) yang menjelaskan hasil penelitiannya di Puskesmas Mangkang kota Semarang untuk pendanaan memang tidak ada dana khusus yang dianggarkan untuk program keselamatan pasien. Namun, menurut kepala Puskesmas Mangkang terdapat dana khusus terkait peningkatan SDM yang dapat dikaitkan dengan keselamatan pasien, jika terdapat pelatihan terkait keselamatan pasien (Islami, Arso and Lestantyo, 2018). UPT Puskesmas harus meningkatkan koordinasi antar bidang terutama program keselamatan pasien agar penggunaan dana tepat sasaran yang dapat mendukung pelaksanaan program keselamatan pasien khususnya dalam proses pengadaan dan pemeliharaan sarana dan prasarana. Selain itu dari hasil telaah dokumen, dana untuk pelaksanaan monitoring dan evaluasi terkait program keselamatan pasien belum pernah dianggarkan oleh manajemen UPT Puskesmas rawat Inap Sukoharjo. Reward berupa pemberian jasa pelayanan kepada tim peningkatan mutu klinis dan keselamatan pasien (PMKP) atau pelatihan juga belum ada. Hal ini berdampak pada kurangnya motivasi tim dalam bekerja.

\section{c. Sarana dan Prasarana}

Ketersediaan sarana dan prasarana untuk pelaksanaan sasaran keselamatan pasien di UPT Puskesmas Rawat Inap Sukoharjo sudah cukup memadai, namun masih ada beberapa sarana dan prasarana yang kurang. Hal ini sejalan dengan penelitian yang dilakukan oleh Sanjaya (2017) bahwa sarana dan fasilitas di Rumah Sakit Pupuk Kalimantan Timur masih belum maksimal. Dari hasil observasinya terdapat tempat tidur pasien yang belum aman, brankar yang tidak aman dan gelang penanda risiko tidak terpasang (Sanjaya, Rosa and Ulfa, 2018). Hasil penelitian lain yang sejalan yaitu penelitian Islami dkk (2018) yang menyatakan bahwa beberapa sarana prasarana penunjang keselamatan pasien, puskesmas Mangkang belum dapat memenuhinya seperti belum adanya pegangan di toilet (Islami, Arso and Lestantyo, 2018). Menurut peneliti beberapa sarana dan prasarana belum terpenuhi ini bisa jadi terkait dengan proses pengadaan barang, pemeliharaan dan disesuaikan RBA puskesmas. Data tentang sarana dan prasarana tiap-tiap sasaran keselamatan pasien di UPT Puskesmas Rawat Inap Sukoharjo belum tersedia, baik dari segi jenis barang, standar kebutuhan, jumlah tersedia dan kondisi saat ini.

\section{d. Kebijakan dan SOP}

Berdasarkan sebagian besar informan kunci mengatakan tentang kebijakan dan SOP sasaran 
keselamatan pasien sudah ada, sudah sesuai permenkes dan undangundang, sudah disosialisasikan ke petugas dan masih terkendala monitoring dan evaluasi yang belum konsisten. UPT Puskesmas Rawat Inap Sukoharjo telah membuat kebijakan dalam bentuk Surat Keputusan Kepala UPT Puskesmas Nomor 440/042.Q/33/2017 tentang kebijakan sasaran-sasaran keselamatan pasien dan mengacu pada permenkes, standar akreditasi dan pedoman penyusunan dokumen akreditasi bagi Fasilitas Kesehatan Tingkat Pertama (FKTP) (Kementerian Kesehatan RI, 2015). Penelitian ini berbeda dengan hasil penelitian Faluzi (2017) yang menunjukkan bahwa kebijakan keselamatan pasien di RSUP Dr. M. Djamil Padang telah membuat regulasi berupa kebijakan internal rumah sakit tentang penerapan standar sasaran keselamatan pasien dan telah membentuk tim Keselamatan Pasien Rumah Sakit (KPRS). KPRS di RSUP Dr. M. Djamil telah melaksanakan tugas dan tanggung jawab sesuai dengan tugas pokok dan fungsinya (Faluzi, Machmud and Arif, 2018).

Berdasarkan informan kunci mengatakan tentang kebijakan dan SOP sasaran keselamatan pasien sudah ada, sudah sesuai permenkes dan undang-undang, sudah disosialisasikan ke petugas dan masih terkendala monitoring dan evaluasi yang belum konsisten. Hal ini sejalan dengan penelitian yang dilakukan oleh Valencia di RSUD Lubuk Basung tentang SOP terkait keselamatan pasien sudah banyak, hanya saja budaya menerapkan SOP masih kurang (Valencia, 2017). Penelitian Islami dkk (2018) menyatakan bahwa untuk sosialisasi

kebijakan/SOP/panduan di puskesmas Mangkang dilaksanakan pada saat rapat seluruh staf dan melalui print out kebijakan yang diberikan kepada masing-masing unit klinis. Pembagian print out dirasa kurang memadai karena kesibukan dan banyaknya pekerjaan dari staf sehingga tempelan kertas hanya dianggap lalu (Islami,
Arso and Lestantyo, 2018). Penelitian lain yang sejalan yaitu penelitian Hidayah (2015) pada puskesmas kecamatan Ambalawi kabupaten Bima Nusa Tenggara Barat. Menjelaskan bahwa puskesmas Ambalawi sudah membuat SOP yang menunjang keselamatan pasien. Namun pelaksanaan yang dilakukan oleh petugas belum sepenuhnya diterapkan, seperti SOP mencuci tangan dan penggunaan sarung tangan di IGD (Hidayah and Mudayana, 2015).

\section{Komponen Proses \\ a. Tidak Terjadinya Kesalahan Identifikasi Pasien}

Berdasarkan hasil telaah dokumen memang ada kebijakan dan SOP yang ditandatangani oleh kepala puskesmas tentang sasaran-sasaran keselamatan pasien salah satunya ketepatan identifikasi pasien. Berdasarkan observasi proses identifikasi pasien di rawat inap UPT Puskesmas Rawat Inap Sukoharjo salah satunya menggunakan gelang identitas pasien dengan tiga identitas yaitu nama, tanggal lahir dan nomor rekam medis pasien. Sesuai dengan pedoman pada SKP 1, tidak boleh menggunakan nomor kamar pasien atau lokasi pasien dirawat (Permenkes R.I No 11, 2017). Penulisan identitas pada gelang pasien di rawat inap wajib dilakukan. Namun masih ada petugas yang lupa memasangkan gelang pasien di rawat inap.

Hal ini sejalan dengan penelitian Sumangkut (2017) yang menunjukkan bahwa Rumah Sakit Umum Gereja Masehi Injil Minahasa GMIM) Kalooran Amurang menggunakan gelang identitas dalam pelaksanaan ketepatan identifikasi pasien (Sumangkut, Kristanto and Pongoh, 2017). Penelitian lain yang sejalan yaitu Anggraini (2015) di puskesmas Kasihan I bantul tentang identifikasi pasien sudah terlaksana. Berdasarkan hasil yang didapatkan dengan persentase menunjukkan bahwa, penerapan patient safety dalam identifikasi pasien sudah terlaksana 
dengan benar. Berdasarkan observasi petugas kesehatan mengidentifikasi minimal 2 identitas pasien menunjukkan 98,30\%. hal ini menunjukkan bahwa mayoritas tenaga kesehatan sudah mengidentifikasi minimal 2 identitas pasien (Anggraini, Anwar and Yulitasari, 2018).

\section{b. Peningkatan Komunikasi Efektif}

Berdasarkan sebagian besar informan kunci mengatakan untuk proses pelaksanaan sasaran keselamatan pasien bermasalah di bagian komunikasi. Berdasarkan hasil sebagian kecil informan FGD profesi mengatakan dalam komunikasi efektif belum menggunakan standarisasi komunikasi melalui metode Situation Background Assessment

Recommendation (SBAR). Sedangkan pada observasi didapatkan bahwa dokter tidak standby 24 jam selama pelayanan. Dapat disimpulkan sementara bahwa peningkatan komunikasi yang efektif di UPT Puskesmas Rawat Inap Sukoharjo belum cukup baik karena dokter tidak standby 24 jam jadi terkadang harus melakukan komunikasi via telepon. Hal ini didukung dengan hasil penelitian telaah dokumen didapatkan belum ada SOP metode komunikasi via telepon di UPT Puskesmas Rawat Inap Sukoharjo menggunakan metode Situation Background Assessment Recommendation (SBAR). Hal ini berbeda dengan hasil penelitian (Keles, Kandou and Tilaar, 2012) di mana pelaksanaan komunikasi efektif di Unit Gawat Darurat RSUD Sam Ratulangi Tondano sudah sesuai standar. Hal ini karena perawat dan dokter selama penelitian tidak pernah memberikan ataupun menerima perintah melalui telepon, karena dokter selalu standby selama jaga (Keles, Kandou and Tilaar, 2012). Penelitian lain juga memberikan hasil yang berbeda, Anggraini (2015) di mana puskesmas Kasihan I Bantul pada penerapan komunikasi yang efektif telah terlaksana dengan baik
(Anggraini, Anwar and Yulitasari, 2018).

\section{c. Tidak Terjadinya Kesalahan Pemberian Obat \\ Berdasarkan sebagian kecil} informan FGD profesi mengatakan pernah terjadi kesalahan pemberian obat. Hal ini juga ditunjang berdasarkan sebagian kecil informan FGD pasien mengatakan pernah tertukar obatnya karena lagi rame. Berdasarkan hasil telaah dokumen, UPT Puskesmas Rawat Inap Sukoharjo telah membuat daftar semua obat yang perlu diwaspadai. Sedangkan berdasarkan observasi untuk obatobatan yang harus diwaspadai sudah memakai stiker berwarna merah dan LASA memakai stiker berwarna biru sebagai penanda. Tempat penyimpanan obat di rawat inap belum sesuai standar, karena obat disimpan di ruang perawat yang suhunya tidak ideal. Lemari khusus penyimpanan obat sudah menggunakan double kunci. Dalam pemberian obat di UPT Puskesmas Sukoharjo sudah berjalan dengan baik, petugas sudah menerapkan prinsip 6 benar dalam pemberian obat.

Hal ini sejalan dengan penelitian (Anggraini, 2018) yang menjelaskan penelitiannya di puskesmas Kasihan Kabupaten Bantul Yogyakarta dalam pemberian obat di Puskesmas Kasihan II sudah berjalan dengan baik, petugas sudah menerapkan prinsip 6 benar dalam pemberian obat, antara lain benar pasien, benar obat, benar jalur, benar dosis, benar kadaluarsa, dan benar informasi (Anggraini, Anwar and Yulitasari, 2018).

\section{d. Tidak Terjadinya Kesalahan Prosedur Tindakan Medis dan Keperawatan}

Agar tidak terjadi kesalahan prosedur tindakan medis dan keperawatan selain ceklis, pasien sebaiknya menjadi mitra dalam menegakkan diagnosis yang tepat, terutama karena mereka yang paling berisiko mengalami kesalahan prosedur tindakan medis dan 
keperawatan (Panesar et al., 2020). Berdasarkan hasil wawancara FGD profesi dan observasi mengenai sasaran keselamatan pasien yang keempat ini, untuk memastikan ketepatan tidak terjadi kesalahan prosedur tindakan medis dan keperawatan, sebagian kecil informan FGD profesi mengatakan belum punya standar operasional prosedur surgical checklist. Hal ini didukung hasil telaah dokumen, pada rekam medis UPT Puskesmas Rawat Inap Sukoharjo belum menggunakan standar operasional prosedur surgical checklist yang dibuktikan dengan tidak ada form surgical checklist yang telah diisi dari data rekam medis pasien. Penandaan operasi pun tidak pernah dilakukan oleh petugas dan melibatkan pasien. Oleh karena itu kepatuhan petugas perlu ditingkatkan agar pelaksanaan sasaran keselamatan pasien khususnya pasien operasi bedah minor dapat berjalan optimal. Berbeda dengan penelitian Keles dkk (2012) dengan judul analisis pelaksanaan standar sasaran keselamatan pasien di Unit Gawat Darurat RSUD Sam Ratulangi Tondano. Di mana Hasil penelitian menunjukkan pelaksanaan kepastian tepat lokasi, tepat prosedur dan tepat pasien operasi sudah sesuai dengan akreditasi rumah sakit versi 2012 (Keles, Kandou and Tilaar, 2012).

Penelitian ini juga berbeda dengan penelitian yang dilakukan oleh Kirana dan Nurmalasari (2017) menjelaskan bahwa pentingnya melibatkan pasien dalam perawatan agar tidak terjadi kesalahan prosedur tindakan medis dan keperawatan dengan pendekatan Patient-Centred Care, adalah dengan melibatkan pasien untuk aktif dalam perawatan kesehatannya sendiri, misalnya pasien berhak menentukan obat dan fasilitas pelayanan kesehatan, serta biaya kesehatan yang harus dikeluarkannya untuk berobat (Kirana and Nurmalasari, 2017).

\section{e. Pengurangan Terjadinya Risiko Infeksi di Puskesmas}

Pokok dari eliminasi infeksi ini adalah cuci tangan (hand hygiene) yang tepat. Pedoman hand hygiene yang berlaku secara internasional bisa diperoleh dari World Health Organization (WHO), puskesmas mempunyai proses kolaboratif untuk mengembangkan kebijakan atau prosedur yang menyesuaikan mengadopsi pedoman hand hygiene yang diterima secara umum untuk implementasi pedoman itu di puskesmas.

Berdasarkan sebagian kecil informan FGD profesi mengatakan sabun cuci tangan, hanscrub atau tissu sering habis. Hal ini di tunjang dengan berdasarkan hasil observasi di lapangan memang untuk sarana dan prasarana cuci tangan masih terdapat kendala seperti wastafel rusak, sabun cuci tangan, handscrub atau tissu yang sering habis. Dari hasil observasi juga, masih ada petugas baik medis maupun paramedis yang belum melaksanakan cuci tangan sesuai dengan prosedur yang telah ditetapkan (5 momen, 6 langkah), termasuk mengedukasi cuci tangan setiap pasien dan keluarga pasien yang berobat di rawat jalan atau di ruangan rawat inap.

Hasil penelitian ini sejalan dengan Keles dkk tahun 2012 yang menunjukkan pengurangan risiko infeksi terkait pelayanan kesehatan belum sesuai dengan standar akreditasi rumah sakit versi $2012 \mathrm{Hal}$ ini terkait dengan kepatuhan petugas dalam menerapkan cuci tangan sesuai dengan pedoman WHO (Keles, Kandou and Tilaar, 2012). Penelitian lain menjelaskan hasil yang berbeda di Puskesmas Kasihan Kabupaten Bantul menjelaskan terkait sasaran keselamatan pasien tentang pengurangan terjadinya infeksi di puskesmas, hasilnya telah terlaksana dengan persentase $86,25 \%$. Selama observasi petugas kesehatan mencuci tangan dengan 6 langkah (Anggraini, Anwar and Yulitasari, 2018). 


\section{f. Tidak Terjadinya Pasien Jatuh}

Berdasarkan hasil FGD profesi pemberi pelayanan di rawat jalan atau rawat inap sebagian kecil informan FGD profesi mengatakan belum ada form penilaian risiko jatuh di dalam rekam medis UPT Puskesmas Rawat Inap Sukoharjo. Berdasarkan wawancara mendalam sebagian kecil informan kunci mengatakan masih ada beberapa sarana dan prasarana yang kurang menunjang dalam pelaksanaan sasaran keselamatan pasien. Hal ini dikuatkan berdasarkan sebagian besar informan FGD pasien mengatakan untuk tempat tidur pasien tidak semua ada penghalangnya. Berdasarkan observasi pada bangsal rawat inap puskesmas, di kamar mandi pasien belum ada satupun terpasang handrail atau pegangan tangan kamar mandi. Tidak semua tempat tidur pasien sudah memiliki besi penghalang atau pengaman dan tidak semua tersedia segitiga kuning yang digantung di tempat tidur pasien yang berisiko jatuh, sehingga memungkinan kejadian risiko jatuh cukup tinggi.

Hasil penelitian ini sesuai dengan penelitian di Puskesmas Mangkang kota Semarang, ketersediaan sarana dan prasarana terkait pengurangan risiko pasien cedera karena jatuh masih belum lengkap seperti handrail di toilet atau pegangan tangan di kamar mandi yang belum mampu puskesmas penuhi (Islami, Arso and Lestantyo, 2018). Hasil penelitian ini berbeda dengan penelitian dimana sasaran keselamatan pasien tentang tidak terjadinya pasien jatuh di Puskesmas Kasihan Kabupaten Bantul sudah terlaksana baik dengan persentase 90,9\% (Anggraini, Anwar and Yulitasari, 2018).

\section{Komponen Output}

Komponen output dari pelaksanaan Sasaran Keselamatan Pasien di UPT Puskesmas Rawat Inap Sukoharjo secara keseluruhan hasil pelaksanaan SKP masih perlu perbaikan. Berdasarkan FGD profesi, semua informan FGD profesi mengatakan mengenai hasil pelaksanaan enam sasaran keselamatan pasien di UPT Puskesmas Rawat Inap Sukoharjo sudah cukup. Rata-rata capaian sasaran keselamatan pasien yaitu 74,03\% dimana standar 100\%. Pelaporan insiden belum pernah dilaksanakan oleh petugas pasca akreditasi tahun 2017.

Hasil penelitian ini senada dengan penelitian (Valencia, 2017) yang menyatakan bahwa program keselamatan pasien di RSUD Lubuk Basung belum tertata dengan baik. $\mathrm{Hal}$ ini disebabkan karena adanya keterbatasan dalam pelaksanaannya, meskipun sudah ada kebijakan tertulis (Valencia, 2017). Penelitian lain yang di puskesmas Mangkang kota Semarang yaitu pelaksanaan program keselamatan pasien belum sesuai dengan penyelenggaraan keselamatan pasien menurut Permenkes No 11 tahun 2017 (Islami, Arso and Lestantyo, 2018). Penelitian Ekasari tahun 2019 menjelaskan bahwa keselamatan pasien menjadi salah satu indikator peningkatan mutu pelayanan Rumah Sakit. Pada program peningkatan mutu pelayanan terdapat 11 indikator laibrary, 9 indikator manajerial dan 6 indikator keselamatan pasien. Salah satu dari ke 9 indikator manajerial yang terdapat di RS Pertamina Bintang Amin adalah harapan dan kepuasan Pasien (Ekasari, 2019).

\section{KESIMPULAN}

Hasil penelitian komponen input tim PMKP dibentuk namun belum bekerja optimal. Belum ada dana khusus untuk keselamatan pasien. Sarana dan prasarana ada beberapa yang kurang. Kebijakan dan SOP sudah ada dan disosialisasikan. Proses belum maksimal, karena belum semua petugas melaksanakan dan belum menjadi budaya bagi petugas. Output belum mencapai target yang diharapkan dengan nilai rata-rata capaian $74,03 \%$ (standar 100\%). 


\section{SARAN}

Disarankan agar puskesmas membuat komitmen, membuat kebijakan yang diperbaharui, melaksanakan pelatihan dan sosialisasi ulang, menyiapkan sarana dan prasarana yang dibutuhkan, menjalankan kebijakan yang ditetapkan, melaksanakan supervisi oleh tim PMKP secara berkala, dan Ka. UPT melakukan pembinaan dan pengawasan tentang keselamatan pasien.

\section{DAFTAR PUSTAKA}

Agustino, L. (2017). Dasar-Dasar Kebijakan Publik. Bandung: Alfabeta.

Amirullah, N. A., A.Pasinringi, S. and Irwandy, K. (2015). Gambaran Budaya Keselamatan Pasien di RSUD Syekh Yusuf Kabupaten Gowa. UNHAS 53(9):1689-1699. doi:

10.1017/CBO9781107415324.00 4.

Anggraini, A. N., Anwar, C. and Yulitasari, B. I. (2018). Hubungan Implementasi IPSG (International Patient Safety Goals) dengan Kepuasan Pasien di Puskesmas Kasihan I Bantul. Journal of Hospital Administration, 1(1). ISSN:26212668. doi:

10.21927/jnki.2015.3(3).162168.

Anggraini, A. N. and Fatimah, F. S. (2015). Evaluasi Penerapan Pasien Safety dalam Pemberian Obat di Wilayah Kerja Puskesmas Kasihan II Bantul Jogjakarta.

Azwar, A. (2010). Pengantar Administrasi Kesehatan. Jakarta: Binarupa Aksara.

Bardan, R. J. (2017). Analisis Penerapan Keselamatan Pasien di Rumah Sakit Umum Daerah Inche Abdoel Moeis Tahun 2017. UNHAS, 1: 1-7. Available at: http://www.albayan.ae.

Cahyono, B. (2012). Membangun Budaya Keselamatan Pasien dalam Praktik Kedokteran. 5th edn. Yogyakarta: Kanisius 2008.
Departemen Kesehatan R.I (2008). Panduan Nasional Keselamatan Pasien Rumah Sakit. Departemen Kesehatan.

Dewi, A. N., Arso, S. P. and Fatmasari, E. Y. (2019). Analisis Pelaksanaan Program Keselamatan Pasien di Unit Rawat Inap RS Wava Husada Kabupaten Malang. Kesehatan Masyarakat Universitas Diponegoro, 7.

Dinas Kesehatan Kabupaten Pringsewu. (2017). Enam Puskesmas di Pringsewu Lulus Akreditasi, Radar Lampung. Available at: https://radarlampung.co.id/2018 /01/17/enam-puskesmas-dipringsewu-lulus-akreditasi/ (Accessed: 2 January 2020).

DUK Puskesmas Rawat Inap Sukoharjo. (2020). Daftar Urut Kepangkatan UPT Puskesmas Rawat Inap Sukoharjo. Pringsewu, Lampung.

Ekasari, F. (2019). Analisis Hubungan Mutu Pelayanan Kesehatan dengan Kepuasan Pasien di Instalasi Gawat Darurat (IGD) RS Pertamina Bintang Amin Lampung 8:53-61.

Faluzi, A., Machmud, R. and Arif, Y. (2018). Analisis Penerapan Upaya Pencapaian Standar Sasaran Keselamatan Pasien Bagi Profesional Pemberi Asuhan Dalam Peningkatan Mutu Pelayanan di Rawat Inap RSUP Dr. M. Djamil Padang Tahun 2017. Jurnal Kesehatan Andalas, 7(2007): $34 . \quad$ doi: 10.25077/jka.v7i0.919.

Handoko, T. H. (2017). Manajemen Personalia dan Sumber Daya Manusia. Yogyakarta: BPFE Yogyakarta.

Hidayah, N. and Mudayana, A. A. (2015). Analisis Penerapan Budaya Keselamatan Pasien di Puskesmas Kecamatan Ambalawi Kabupaten Bima Nusa Tenggara Barat.pdf.

Islami, K., Arso, S. P. and Lestantyo, D. (2018). Analisis Pelaksanaan 
Program Keselamatan Pasien

Puskesmas Mangkang, Kota

Semarang. Jurnal Kesehatan

Masyarakat 53(9):1689-1699.

doi:

10.1017/CBO9781107415324.00 4.

KARS. (2017). Standar Nasional Akreditasi Rumah Sakit. Kementerian Kesehatan Republik Indonesia.

Keles, A. W., Kandou, G and Tilaar, C. (2012). Analisis Pelaksanaan Standar Sasaran Keselamatan Pasien di Unit Gawat Darurat RSUD Dr . Sam Ratulangi Tondano Sesuai dengan Akreditasi Rumah Sakit Versi 2012: 250-259.

Kementerian Dalam Negeri RI. (2016). Peraturan Menteri Dalam Negeri Republik Indonesia Nomor 61 Tahun 2007 Tentang Pedoman Teknis Pengelolaan Keuangan Badan Layanan Umum Daerah. (1038).

Kementerian Kesehatan Republik Indonesia. (2019). Prakarsa Indonesia Pada Pertemuan Ministerial Summit On Patient Safety, Kementerian Kesehatan Republik Indonesia. Available at: https://www.kemkes.go.id/articl e/print/19030400004/prakarsaindonesia-pada-pertemuanglobal-ministerial-summit-onpatient-safety.html (Accessed: 2 January 2020).

Kementerian Kesehatan Republik Indonesia. (2014). Buku Standar Akreditasi Puskesmas. Jakarta.

Kementerian Kesehatan RI. (2015). Pedoman Penyusunan Dokumen Akreditasi Fasilitas Kesehatan Tingkat Pertama (FKTP). Jakarta: Direktorat Jenderal Bina Upaya Kesehatan Direktorat Bina Upaya Kesehatan Dasar.

Kirana, G. R. and Nurmalasari, I. (2017). Pentingnya Standarisasi Prosedur Keselamatan Pasien di Puskesmas X Kabupaten Kediri. Kesehatan Masyarakat Fakultas IImu Kesehatan Bhakti Wijaya Kediri.
Komite Keselamatan Pasien Rumah Sakit (2015). Pedoman Pelaporan Insiden Keselamatan Pasien (IKP) Patient Safety Incident Report. KOMITE KESELAMATAN PASIEN RUMAH SAKIT: 25.

Neri, R. A., Lestari, Y. and Yetti, H. (2018). Analisis Pelaksanaan Sasaran Keselamatan Pasien di Rawat Inap Rumah Sakit Umum Daerah Padang Pariaman. jurnal.fk.unand.ac.id: 2-31.

Notoatmodjo, S. (2012). Metodologi Penelitian Kesehatan. Jakarta: Rhineka Cipta.

Panesar, S. S. et al. (2020). Keselamatan Pasien dan Peningkatan Mutu Pelayanan Kesehatan. 4th edn. Edited by Sutoto and N. A. Lumenta K. Nefro. Jakarta: Erlangga.

Permenkes R.I No 11. (2017). Peraturan Menteri Kesehatan Republik Indonesia Nomor 11 Tahun 2017 Tentang Keselamatan Pasien. PERMENKES $7(1): 45-56$.

Permenkes R.I No 1691. (2011). Peraturan Menteri Kesehatan Republik Indonesia Nomor 1691 Tahun 2011 Tentang Keselamatan Pasien Rumah Sakit. PERMENKES 156: 315322.

Permenkes R.I No 46. (2015). Akreditasi Puskesmas, Klinik Pratama, Tempat Praktik Mandiri Dokter, Dan Tempat Praktik Mandiri Dokter Gigi.

Profil Puskesmas Rawat Inap Sukoharjo. (2020). Profil UPT Puskesmas Rawat Inap Sukoharjo 2020. Pringsewu Lampung: Puskesmas Rawat Inap Sukoharjo.

Rachmawati, N. and Harigustian, Y. (2019). Manajemen Patient Safety Konsep \& Aplikasi Patient Safety dalam Kesehatan. Yogyakarta: PT. Pustaka Baru.

RBA Puskesmas Rawat Inap Sukoharjo. (2020). Rencana Belanja Anggaran Puskesmas Rawat Inap Sukoharjo Tahun 
2020. Pringsewu, Lampung.

Sanjaya, P. D., Rosa, E. M. and Ulfa, M. (2018). Evaluasi Penerapan Pencegahan Pasien Berisiko Jatuh di Rumah Sakit. Kes Mas: Jurnal Fakultas Kesehatan Masyarakat, 11(2): 105-113. doi: 10.12928/kesmas.v11i2.6013.

Sugiyono. (2017). Metode Penelitian Kuantitatif, Kualitatif, dan R\&D. 26th edn. Bandung: Alfabeta.

Sumangkut, N. S. I., Kristanto, E. and Pongoh, J. (2017). Evaluasi Penatalaksanaan Sasaran Keselamatan Pasien Di Rumah Sakit UMUM GMIM Kalooran Amurang: 56-73.

TIM PMKP UPT Puskesmas Rawat Inap Sukoharjo. (2017). Rencana Tahunan Tim Peningkatan Mutu Klinis dan Keselamatan Pasien. Pringsewu, Lampung.

Ulumiyah, N. H. (2018). Meningkatkan Mutu Pelayanan Kesehatan Dengan Penerapan Upaya Keselamatan Pasien di Puskesmas. JAKI ERLANGGA, 6(2):149-155. doi: 10.20473/jaki.v6i2.2018.149155.

Valencia. (2017). Analisis Pelaksanaan Program Keselamatan Pasien. Unand.

Yusuf, A. M. (2019). Metode Penelitian Kuantitatif, Kualitatif \& Penelitian Gabungan. 5th edn. Jakarta: Prenada Media Group. 